\title{
Cue or place learning in one-way avoidance acquisition?
}

\author{
PAUL R. SOLOMON, DANIEL J. SULLIVAN, GWEN L. NICHOLS, and \\ JOSEPH M. KIERNAN III \\ Williams College, Williamstown, Massachusetts 01267
}

\begin{abstract}
The results of two experiments suggest that neither nominal nor apparatus-produced CSs are necessary for the acquisition of the one-way avoidance response. In contrast to the results of studies using a variety of tasks, stimulus preexposure does not disrupt conditioning in the one-way avoidance task. Animals given 30 preexposures to a tone CS, a movable door CS, or a compound consisting of both acquired the avoidance response at the same rate as nonpreexposed controls (Experiment 1). A second experiment demonstrated that 90 preexposures to the compound CS also did not retard conditioning. These data, combined with videotaped observations of animals during CAR acquisition, suggest that one-way avoidance is acquired via the association of a place (the shock compartment) rather than a cue with the UCS.
\end{abstract}

In the typical one-way avoidance task, the animal is required to avoid shock by jumping onto a platform in the presence of a warning signal. Early accounts of avoidance learning (e.g., Miller, 1951; Mowrer, 1960) suggested that the CS served as a warning signal and that its termination was fear reducing (reinforcing). More recent accounts, however, indicate that although the CS is important in two-way and Sidman avoidance tasks, it is not critical in one-way avoidance acquisition. Specifically, Bolles (1972) suggested that in the one-way avoidance task, the animal learns to avoid the shock compartment by associating the UCS with this area. Testa (1974) has taken this analysis one step further by specifying the apparatus cues that are likely to be associated with the shock UCS. Testa suggested that since the shock grid shows similarity to the shock UCS in terms of both location and temporal intensity, it should be most readily associated with the shock. Thus, whereas the earlier accounts of avoidance learning assume that the one-way task is acquired by the association of the CS and UCS (cue learning), the more recent view maintains that the avoidance response is learned by an association between a place (the shock compartment and perhaps, more specifically, the grid) and the UCS.

The purpose of the present investigation was to evaluate the relative contributions of place and cue learning in one-way avoidance acquisition. Specifically,

Parts of this research were supported by National Science Foundation Grant BNS-77-14871 and a faculty research grant from Williams College to Paul R. Solomon. We would like to thank B. Babcock, R. Garand, J. McCann, and E. Ouellette for their technical assistance. Requests for reprints should be sent to Paul R. Solomon, Department of Psychology, Williams College, Williamstown, Massachusetts 01267. the present study investigated the role of both nominal and apparatus-produced CSs in the one-way paradigm by degrading the informational value of the cue prior to conditioning.

One method of degrading the informational value of a CS is to present the CS and not follow it by either a rewarding or an aversive event. This procedure of preexposing a stimulus is called latent inhibition (LI) and typically results in retarded response acquisition when the stimulus is subsequently paired with a UCS in a conditioning paradigm (see Lubow, 1973, for a review). Experimental investigations of this phenomenon in a variety of preparations including conditioned emotional response (Rescorla, 1971), rabbit nictitating membrane response (Reiss \& Wagner, 1972; Solomon, Brennan, \& Moore, 1974), and two-way avoidance (Solomon, Kiney, \& Scott, 1978) suggest that the LI effect is due to the preexposed CS losing cue value via a tuning-out process resembling habituation.

The present experiment sought to evaluate the role of a nominal CS (tone), an apparatus-produced CS (door movement), and a compound CS consisting of both in a one-way task by using the LI paradigm. If any of these cues are critical to the task, preexposed animals should acquire the avoidance response more slowly than nonpreexposed controls.

\section{Subjects}

\section{METHOD}

Thirty-two naive male Sprague-Dawley derived rats between the ages of 120 and 150 days were used as subjects. Animals were individually housed in a colony room with a 12-h light, 12-h dark cycle. Food and water were available ad lib.

\footnotetext{
Apparatus

The conditioning apparatus was a modification of the Lafayette Instrument Model 85200 one-way automated
} 
shuttlebox. The shock chamber had a floor that consisted of 15 stainless steel grids and was $22.9 \mathrm{~cm}$ long, $21.6 \mathrm{~cm}$ wide, and $21.0 \mathrm{~cm}$ high. The escape platform was located $7.6 \mathrm{~cm}$ above the grid floor and was $21.6 \mathrm{~cm}$ wide, $15.2 \mathrm{~cm}$ deep, and $21.0 \mathrm{~cm}$ high. The animal was given access to the escape platform by retracting a movable door that had a travel time of $2 \mathrm{sec}$ in each direction. The entire apparatus was housed in a soundattenuated chamber.

The apparatus was constantly illuminated by a $6-\mathrm{W}$ bulb located on the wall opposite the escape platform. A speaker located on the roof of the shock compartment delivered the white noise $\left(60 \mathrm{~dB}\right.$, re: $\left.20 \mu \mathrm{N} / \mathrm{m}^{2}\right)$ and the tone CS.

Experimental contingencies were controlled by programming equipment in an adjacent room, and the behavior of the animals was monitored via a closed-circuit television system.

\section{Procedure}

Animals were randomly assigned to a tone preexposure group (Group PE-T), a movable door preexposure group (Group PE-D), a tone plus movable door preexposure group (Group PE-T+D), or a nonpreexposed control condition (Group CON). There were eight animals in each condition.

Testing took place during a single session that was divided into three stages. Stage 1 was the same for all animals and consisted of a 5-min free exploration period of the shock compartment, during which the movable door was closed. During Stage 2, animals in the PE-T group received 30 preexposures to the tone. Each preexposure lasted $10 \mathrm{sec}$ and raised the sound pressure level in the chamber to $80 \mathrm{~dB}$ (re: $20 \mu \mathrm{N} / \mathrm{m}^{2}$ ). Animals in Group PE-D received 30 preexposures to the door retraction. During each preexposure, the door was fully retracted for a 10-sec period, after which it was returned to the closed position. Animals in Group PE-D+T received 30 preexposures to a compound consisting of both the tone and door. The interpreexposure interval varied from 15 to $75 \mathrm{sec}$ around a mean of $30 \mathrm{sec}$. For animals in the CON group, Stage 2 was simply a $15-$ min extension of Stage 1 . Stage 3 was the same for all animals and consisted of acquisition of the conditioned avoidance response. Each trial was signaled by the onset of the tone and the retraction of the door. If the animal failed to jump onto the escape platform within $10 \mathrm{sec}$, a $.5-\mathrm{mA}$ shock was delivered and remained on until the animal jumped onto the escape platform. The escape response terminated both the tone and shock. If the animal jumped onto the platform during the 10-sec CS period, that is, emitted a conditioned avoidance response (CAR), the tone was terminated and the shock avoided. On both escape and avoidance trials, the animal was allowed to remain on the platform for $10 \mathrm{sec}$ and was then gently pushed back onto the grid floor. The intertrial interval (ITI) during Stage 3 was the same as during the preexposure period, and the movable door remained closed during this time.

All animals were run to a criterion of eight CARs in any block of 10 trials and for a minimum of 50 trials.

\section{RESULTS AND DISCUSSION}

Table 1 shows the mean number of trials to reach a criterion of eight CARs in any block of 10 trials, as well as the total number of CARs out of 50 possible trials for Groups CON, PE-T, PE-D, and PE-D+T. An analysis of variance between the group means indicated no significant differences between the groups on either dependent measure $[\mathrm{Fs}(3,28)<1$, ps $>.05]$. Similarly, an analysis of the mean latencies for all avoidance trials revealed no reliable differences between the four groups $[F(3,28)<1, p>.05]$. Table 1 also shows the mean latencies for each condition.
Table 1

Mean Number of Trials to Reach a Criterion of Eight CARs in any Block of 10 Trials, Mean Total CARs, and Mean Latency on All Avoidance Trials for Animals in Each of the Four Groups

\begin{tabular}{lccc}
\hline Group & $\begin{array}{c}\text { Trials to } \\
\text { Criterion }\end{array}$ & CARs* & Latency \\
\hline PE-T & 31.7 & 32.5 & 1.9 \\
PE-D & 31.3 & 28.3 & 2.2 \\
PE-D+T & 32.0 & 30.6 & 2.3 \\
CON & 29.6 & 27.9 & 2.0 \\
\hline
\end{tabular}

*50 possible.

In contrast to the findings of studies that used other avoidance paradigms (cf. Lubow, 1973), the present study failed to find any retardation of conditioning following stimulus preexposure. These data suggest that neither the tone, the door, nor a compound consisting of both was a critical cue in the acquisition of the CAR. There is the possibility that 30 preexposures are not sufficient to produce a retardation of conditioning in the one-way avoidance paradigm. This, however, seems unlikely. A number of earlier studies using the two-way avoidance task indicated that 30 preexposures were sufficient to produce a marked retardation of conditioning (Ackil, Mellgren, Halgren, \& Frommer, 1969; Solomon et al., 1978; Weiss, Friedman, \& McGregor, 1974), and one study (Wilson, Phinney, \& Brennan, 1974 ) indicated that 10 preexposures were sufficient. Similarly, Lubow (1973) reviewed the effects of the number of preexposures on the LI effect and reported that in most preparations, a range of 16-20 preexposures is sufficient to produce a significant retardation of conditioning.

Nevertheless, to test this possibility in the present paradigm, two additional groups of eight animals were tested. One group was given 90 preexposures to the door plus tone CS, while the remaining group simply sat in the apparatus for a corresponding amount of time (45 $\mathrm{min}$ ). The mean number of trials to reach a criterion of eight CARs in any block of 10 trials for the preexposed group was 31.6, whereas the mean number trials in the control group was 28.5. A t test indicated that the difference between these two groups was not significant $[\mathrm{t}(14)=1.13, \mathrm{p}>.05]$. Similarly, a comparison of all six experimental conditions revealed no reliable differences between the groups $[F(5,42)<1$, $\mathrm{p}>.05]$.

The data from this study suggest that none of the CSs present in the one-way avoidance task is critical to the acquisition of the CAR. This implies that the avoidance response in this paradigm is acquired by means other than associations between nominal or apparatus-produced CSs and the UCS. It is possible, as Bolles (1972) and Testa (1974) suggested, that the animal learns to avoid the shock compartment by associating the UCS with this area. This would constitute a form of place learning. Support for this view comes 
from examination of videotape taken of the animals during CAR acquisition. Specifically, we were able to predict whether or not an animal would make an avoidance response based on its behavior just prior to the CS onset. During the first few trials that an animal emitted avoidance responses, it typically faced the door during the ITI. As the CAR was acquired, most animals reared on their hind legs with their front paws resting on the door. At the CS onset, these animals actually fell into the safe compartment. This behavior, which usually lasted during the entire ITI, seems to indicate that the animal learned the shock compartment was a dangerous place.

Additional support for this view comes from three animals that we ran in an attempt to eliminate the door CS. In this situation, the door was retracted at all times and a tone served as the nominal CS. If the animal made a response during the ITI, it was immediately pushed off the platform; if a response was made in the presence of the CS, the tone was terminated and the animal was permitted to remain on the platform for $15 \mathrm{sec}$. This procedure was abandoned since each animal consistently jumped on the platform during the ITI.

In summary, the data from the present study indicate that associations between the nominal and apparatusproduced CSs and UCS are not critical to one-way avoidance. Rather, it appears that the animal learns that one place, the shock compartment, is dangerous and attempts to avoid it.

\section{REFERENCES}

Ackil, J. E., Mellgren, C., Halgren, C., \& Frommer, G. P. Effects of CS preexposure on avoidance learning in rats with hippocampal lesions. Journal of Comparative and Physiological Psychology, 1969, 69, 739-747.

Bolles, R. C. The avoidance learning problem. In G. H. Bower (Ed.), Psychology of learning and motivation. New York: Academic Press, 1972.

Luвow, R. E. Latent inhibition. Psychological Bulletin, 1973, 79, 398-407.

Miller, N. E. Learnable drives and rewards. In S. S. Stevens (Ed.), Handbook of experimental psychology. New York: Wiley, 1951.

MOWRER, O. H. Learning theory and behavior. New York: Wiley, 1960.

ReISS, S., \& WAGNER, A. R. CS habituation produces a "latent inhibition effect" but no "conditioned inhibition." Learning and Motivation, 1972, 3, 237-245.

RESCORLA, R. A. Variation in the effectiveness of reinforcement and nonreinforcement following prior inhibitory conditioning. Learning and Motivation, 1971, 2, 113-123.

Solomon, P. R., Brennan, G., \& Moore, J. W. Latent inhibition of the rabbit's nictitating membrane response as a function of CS intensity. Bulletin of the Psychonomic Society, 1974, 4, 445-447.

Solomon, P. R., Kiney, C. A., \& Scott, D. S. Disruption of latent inhibition following systemic administration of parachlorophenylalanine (PCPA). Physiology \& Behavior, 1978, 20, 265-271.

TEsta, T. Causal relationships and the acquisition of avoidance responses. Psychological Bulletin, 1974, 81, 491-505.

Weiss, K. R., Friedman, R., \& McGregor, S. Effects of septal lesions on latent inhibition and habituation of the orienting response in rats. Acta Neurobiologica Experimentalis, 1974, 34, 491-504.

Wilson, L. M., Phinney, R. L., \& Brennan, J. F. Agerelated differences in avoidance behavior in rats following CS preexposure. Developmental Psychobiology, 1974, 1, 421-427.

(Received for publication January 16, 1979.) 